\title{
Elevational pattern of bird species richness and its causes along a central Himalaya gradient, China
}

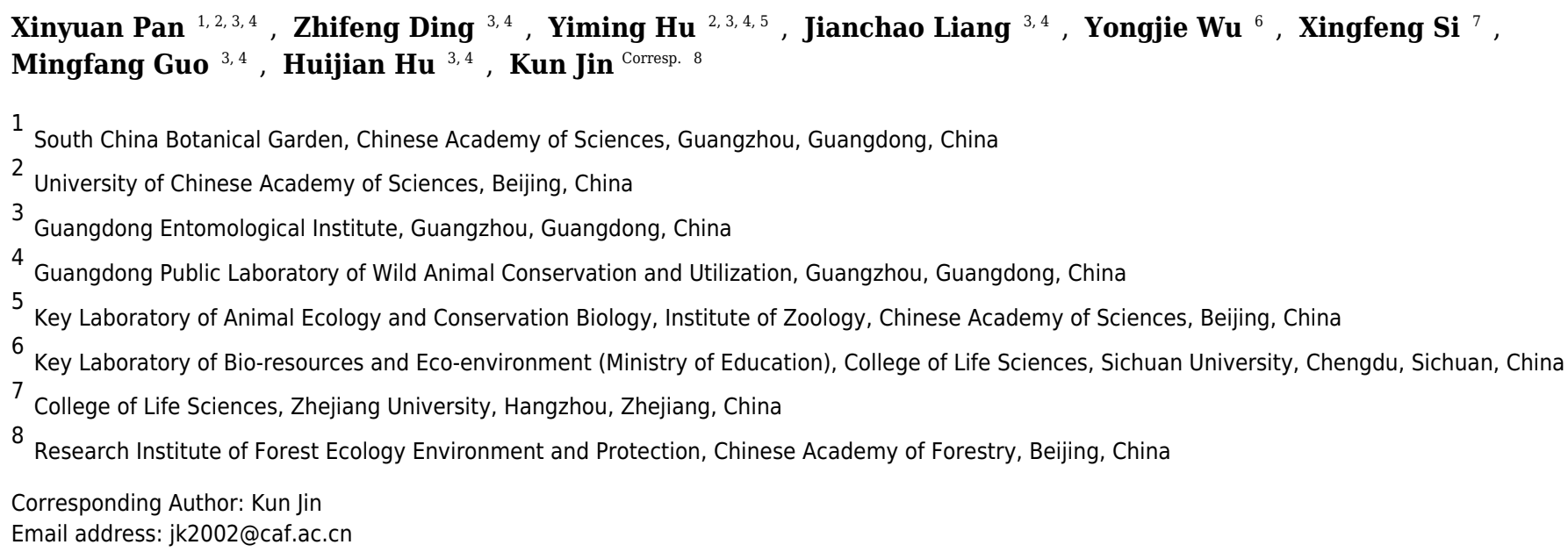

To improve our understanding of mechanisms underlying biodiversity patterns, and provide valuable insights for conservation biologists, elevational pattern of bird species richness and its causes were studied along a central Himalaya gradient, China for the first time. We conducted field surveys at each of twelve elevational bands of $300 \mathrm{~m}$ for four times throughout the whole wet season between $1800-5400 \mathrm{~m}$ asl. A total of 169 breeding bird species were recorded, belonging to 11 orders, 41 families and 100 genera. Species richness patterns of overall breeding birds, large-ranged and small-ranged species were all hump-shaped, and peaked at the 2700-3000 m asl (overall), 3300-3600 m asl (largeranged species), whereas small-ranged species had two peaks, with the larger peak occurring at the 2700-3000 m asl and the smaller peak at the 3600-3900 m asl. Area and precipitation were not crucial factors in determining species richness along this gradient. Productivity, habitat heterogeneity $(\mathrm{HH})$ and the mid-domain effect (MDE) all played important role in shaping elevational richness patterns of birds in individual regression analyses. In the multiple regressions, productivity and $\mathrm{HH}$ were strong explanatory factors for most of the bird groups, with MDE contributing to richness pattern of large-ranged species. Our results highlight the conservation necessity of primary forest and intact habitat in this montane biodiversity hotspot. 
1 Elevational pattern of bird species richness and its causes along a central

2 Himalaya gradient, China

3 Xinyuan Pan ${ }^{1,2,3,4}$, Zhifeng Ding ${ }^{3,4}$, Yiming $\mathrm{Hu}^{2,3,4,5}$, Jianchao Liang ${ }^{3,4}$, Yongjie $\mathrm{Wu}^{6}$, Xingfeng $\mathrm{Si}^{7}$,

4 Mingfang Guo ${ }^{3,4}$, Huijian $\mathrm{Hu}^{3,4^{*}}$, Kun $\mathrm{Jin}^{8^{*}}$

$5{ }^{1}$ South China Botanical Garden, Chinese Academy of Sciences, Guangzhou, Guangdong, China

$6{ }^{2}$ University of Chinese Academy of Sciences, Beijing, China

$7 \quad{ }^{3}$ Guangdong Institute of Applied Biological Resources, Guangzhou, Guangdong, China

$8{ }^{4}$ Guangdong Public Laboratory of Wild Animal Conservation and Utilization, Guangzhou,

9 Guangdong, China

$10{ }^{5}$ Key Laboratory of Animal Ecology and Conservation Biology, Institute of Zoology, Chinese

11 Academy of Sciences, Beijing, China

$12{ }^{6}$ Key Laboratory of Bio-resources and Eco-environment (Ministry of Education), College of Life

13 Sciences, Sichuan University, Chengdu, Sichuan, China

$14{ }^{7}$ College of Life Sciences, Zhejiang University, Hangzhou, Zhejiang, China

$15{ }^{8}$ Research Institute of Forest Ecology Environment and Protection, Chinese Academy of Forestry,

16 Key Laboratory of Forest Ecology Protection, State Forestry Administration, Beijing, China

17 Corresponding authors:

18 Huijian $\mathrm{Hu}$

19105 Xingang West Road, Guangzhou, Guangdong, 510260, China.

20 Email address: 13922339577@139.com

21 Kun Jin

22 Xiangshan Road behind the Summer Palace, Beijing, 100091, China.

23 Email address: jk2002@caf.ac.cn 
24 Abstract

25 Elevational patterns of bird species richness and their causes were studied along a central Himalaya gradient for the first time in the Gyirong Valley, the longest of five canyons in the Mount Qomolangma National Nature Reserve. We conducted field surveys in each of twelve elevational bands of 300 m between 1800 and $5400 \mathrm{~m}$ asl four times throughout the entire wet season. A total of 169 breeding bird species were recorded, belonging to 11 orders, 41 families and 100 genera. Most of the birds (74\%) were small-ranged. The species richness patterns of overall breeding birds and large-ranged birds were all hump-shaped and peaked at 2700-3000 m asl (overall) and 3300-3600 m asl (large-ranged species), whereas small-ranged species had two peaks, with the larger peak occurring at 2700-3000 m asl and the smaller peak at 3600-3900 m asl. Large-ranged species and small-ranged species contributed equally to the overall richness pattern. in this area. Furthermore, we need to increase conservation efforts in this montane biodiversity hotspot in light of increasing anthropogenic activities and land use pressure. 


\section{Introduction}

48 Geographical variation in biodiversity is one of the most conspicuous patterns in biology.

Developing an understanding of this variation has been of interest to naturalists and biogeographers ever since Darwin and Wallace (Heaney, 2001) and has taken on new urgency since ongoing human activities may soon lead to the extinction of the majority of extant species (Dirzo \& Raven, 2003; Wiens, 2011). Altitudinal gradients have received much attention in recent decades and have become increasingly popular for uncovering the underlying mechanisms of the spatial variation in diversity, owing to various advantages compared to latitudinal gradients (e.g., globally replicated gradients, smaller spatial scale and constancy in the ecological and historical context of the faunal assemblage) (McCain, 2009).

Traditionally, species richness has been considered to decrease monotonically with increasing elevation because of reduced temperatures and a consequent decrease in productivity (Rohde, 1992; Stevens, 1992). However, when standardized for area effects and sampling effort, different elevational patterns emerge, which can generally be grouped into four categories: a decrease in species richness with elevation, a low-elevation plateau followed by a decrease, a low-elevation plateau with a mid-elevation peak, and a unimodal mid-elevation peak (Rahbek, 1995; Rahbek, 2005). Numerous hypotheses have been proposed to explain both linear and humped relationships between species richness and altitude (Rahbek, 1997; Lomolino, 2001; McCain, 2007a; McCain, 2007b; Wu et al., 2013b; Rowe, Heaney \& Rickart, 2015). Generally, spatial (e.g., area, mid-domain effect (MDE)) (Rahbek, 1997; Colwell, Rahbek \& Gotelli, 2004) and environmental factors (e.g., climatic variables, productivity and habitat heterogeneity) (Nogués-Bravo et al., 2008; Sanders \& Rahbek, 2012; Wu et al., 2013b) are the most frequently cited explanations for the variation in species richness. 
Area has been found to explain a large proportion of the elevational species richness patterns

71 (Rahbek, 1997), and subsequent studies have confirmed the role of area in shaping species

richness patterns (Fu et al., 2004; Kattan \& Franco, 2004; McCain, 2005; Williams et al., 2010).

The MDE is defined as "the increasing overlap of species ranges towards the center of a shared, bounded domain owing to geometric boundary constraints” (Colwell \& Hurtt, 1994; Colwell, Rahbek \& Gotelli, 2004) and has been suggested to explain a substantial proportion of the elevational variation in richness (McCain, 2004; Cardelús, Colwell \& Watkins, 2006; Kluge, Kessler \& Dunn, 2006; Rowe, 2009; Wu et al., 2013a; Wu et al., 2013b). ‘temperature’ below) and mean annual precipitation (MAP, also referred to as ‘precipitation’ below), are considered to be the most widely supported environmental predictors of biodiversity patterns (Hawkins et al., 2007; McCain, 2007b; Wu et al., 2013a; Wu et al., 2013b). Temperature and precipitation can influence biodiversity both directly through physiological tolerances and indirectly by affecting food resource availability (Currie et al., 2004; McCain, 2009; Rowe et al., 2015). The niche conservatism hypothesis proposes that most modern species originated when the majority of the Earth was experiencing tropical-like conditions and that these species tend to retain their ancestral ecological characteristics. Thus, there will be high species richness in regions characterized by warm temperatures and abundant rainfall (Wiens \& Donoghue, 2004). more species rather than larger populations of existing species (Hutchinson, 1959; MacArthur, 91 1972; Wright, 1983). As a proxy for energy availability, primary productivity has often been

92 estimated using the normalized difference vegetation index (NDVI). Previous studies on birds 
93 have reported a positive relationship between the NDVI and species richness (Hurlbert \&

94 Haskell, 2003; Lee et al., 2004; Hawkins, Diniz-Filho \& Soeller, 2005; Koh, Lee \& Lin, 2006;

95 Wu et al., 2013b). The habitat heterogeneity (HH) hypothesis states that more habitat types or

96 greater structural complexity in vegetation can provide more resources and may therefore support

97 a larger number of species (MacArthur \& MacArthur, 1961). HH appears to have been less

98 frequently tested than climatic factors in previous studies, possibly because of difficulties

99 associated with measuring this variable; for example, the relevant type of heterogeneity will

100 depend on the taxa studied and on the scale of the study (Heaney, 2001; Rowe, 2009). However,

101 when taken into account, a positive role of $\mathrm{HH}$ in shaping species richness patterns is often

102 significant (Sánchez-Cordero, 2001; Hurlbert \& Haskell, 2003; Hurlbert, 2004; Koh et al., 2006;

103 Rowe, 2009).

104 Most studies of the determinants of geographic patterns in species richness have

105 traditionally focused only on overall species richness patterns. However, geographic patterns in

106 overall species richness are usually dominated by wide-ranging species because their larger

107 number of distribution records has a disproportionate contribution to the species richness counts

108 than do narrow-ranging species. The geographic range size could influence our understanding of

109 what determines species richness (Jetz \& Rahbek, 2002). Some studies have demonstrated that

110 different patterns and processes determine the elevational diversity of large-ranged and small-

111 ranged species (Cardelús, Colwell \& Watkins, 2006; Kluge, Kessler \& Dunn, 2006; Wu et al., 112 2013b).

113 Despite two centuries of investigation, the mechanisms shaping species richness patterns 114 along elevational gradients remain controversial (Rahbek, 2005; Rowe, 2009). Comparing 115 independent transects and searching for similarities and differences in patterns among transects 
116

117

118

and taxa in different climates and biogeographic regions can certainly improve our understanding of the mechanisms underlying biodiversity patterns (Grytnes \& McCain, 2007). The Himalayas contain the highest mountains in the world, with a diverse range of eco-climate zones (Dobremez, 1976), and are one of the world's biodiversity hotspots (Myers et al., 2000). Mountains with a broad range of elevation such as this have been considered ideal systems for elevational diversity studies (Acharya et al., 2011).

Previous studies in this region have focused on plants (Grytnes \& Vetaas, 2002; Bhattarai \& Vetaas, 2003; Oommen \& Shanker, 2005; Bhattarai \& Vetaas, 2006; Acharya, Vetaas \& Birks, 2011) and reptiles (Chettri, Bhupathy \& Acharya, 2010), revealing a predominant unimodal pattern. For the elevational pattern of birds, one study from the Nepal Himalayas found that species richness decreased with increasing elevation (Hunter \& Yonzon, 1993). Two descriptive studies from the central Himalayas, China, showed hump-shaped richness patterns of overall bird species (Li et al., 2013; Hu, Jin \& Tian, 2016). Acharya et al. (2011) found that bird species richness along an eastern Himalaya gradient peaked at mid-elevations and was significantly correlated with primary productivity and habitat variables. A study of songbirds in the eastern Himalayas demonstrated a hump-shaped elevational richness pattern and found that elevational distributions were well-explained by resource availability (Price et al., 2014). One study of birds in the western Himalayas showed a hump-shaped elevational richness pattern and a significant correlation between species richness and vegetation structure (Joshi \& Bhatt, 2015). Considering that the mechanisms underlying elevational patterns vary even among gradients with similar biogeographic histories and fauna (Rowe, 2009), new, optimally designed elevational studies and integrative analyses of biodiversity along central Himalaya gradients in China are important for understanding these complex patterns and their underlying mechanisms (Grytnes \& McCain, 
139

140

141

142

143

144

145

146

2007; Wu et al., 2013a) and for the management and conservation of biodiversity.

In this study, we document the elevational species richness patterns of birds (using data obtained from a field survey in the Gyirong Valley, which is located on the southern slope of the central Himalayas, China) and assessed the ability of two spatial factors (area, MDE) and four environmental factors (MAT, MAP, NDVI and HH) to explain elevational patterns of bird species richness.

\section{Materials and Methods}

\section{Study area}

The Gyirong Valley $\left(28^{\circ} 15^{\prime}-29^{\circ} 0^{\prime} \mathrm{N}, 85^{\circ} 6^{\prime}-85^{\circ} 41^{\prime} \mathrm{E}\right.$, Fig. 1) is the longest of the five canyons in the Mount Qomolangma National Nature Reserve and is characterized by an ecotone between the Oriental and Palearctic regions. This valley ranges from 1680 to $5770 \mathrm{~m}$ asl, with a complicated geological structure, varied geomorphologic types and rich biodiversity. The total area of this valley is $2612 \mathrm{~km}^{2}$. Located in the subtropical monsoon climate zone, the valley is influenced by the warm, moist flow from the Indian Ocean and has distinct wet and dry seasons: the rainy season occurs from May to October, with the majority of rainfall occurring in July to September, and the dry season lasts from November to April.

There are five vegetation zones along the elevational gradient (Feng, Cai \& Zheng, 1986; The Comprehensive Scientific Expedition to Qinghai-Xizang Plateau, Chinese Academy of Sciences, 1988): evergreen broadleaf forest (1700-2500 m asl), coniferous and broadleaf mixed forest (2500-3300 m asl), dark coniferous forest (3300-3900 m asl), shrub and grass (3900-4700 $\mathrm{m}$ asl) and alpine tundra with sparse grass (4700-5500 $\mathrm{m}$ asl). 


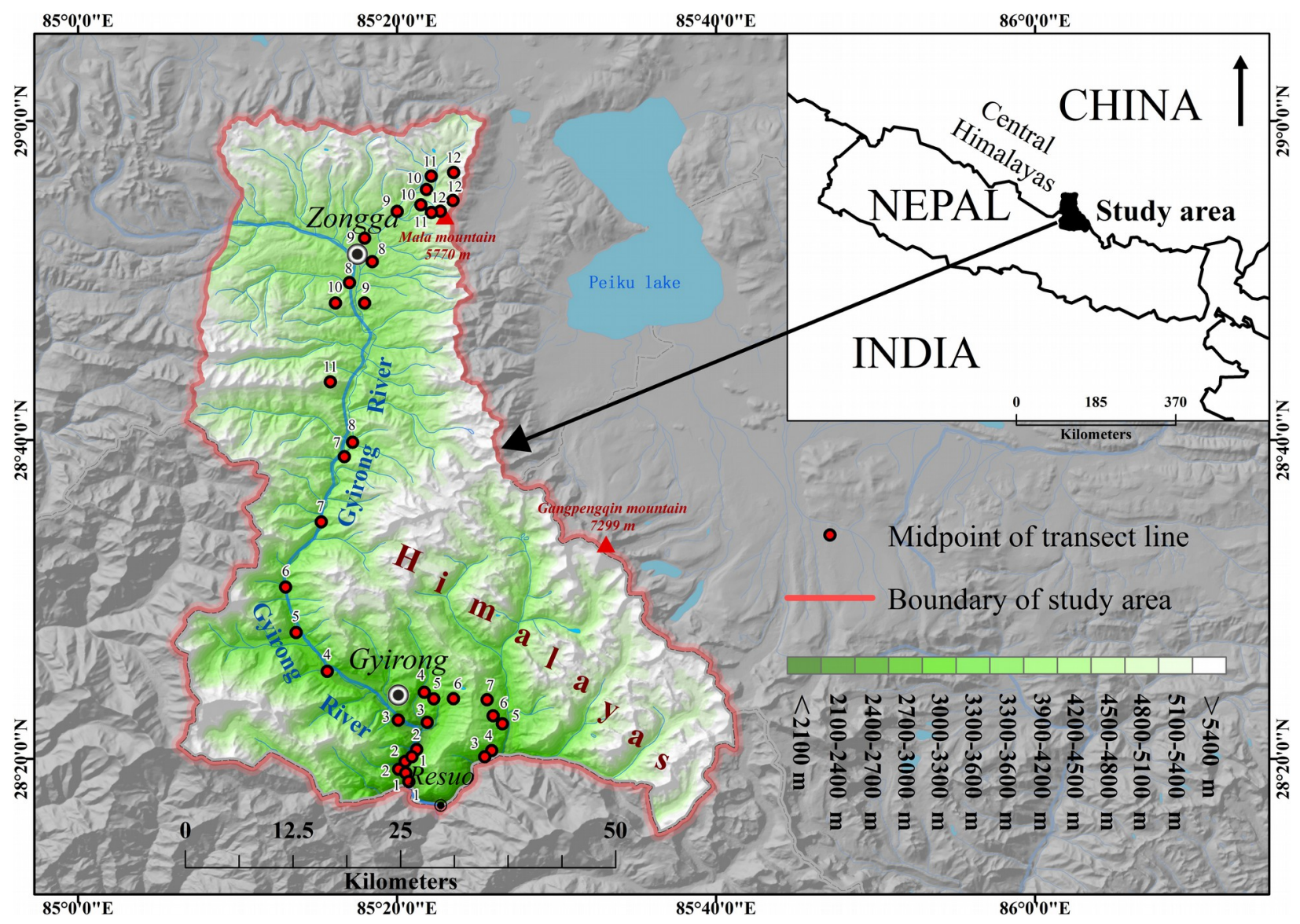

Figure 1: Location of the study area. The study area encompasses 12 sampling elevational bands. The numbers from 1 to 12 are the midpoints of transect lines distributed in the 12 elevational bands from the lowest elevation to the highest elevation (e.g., "1" was the midpoint of the transect lines distributed in the lowest elevational band).

\section{Bird surveys}

Field surveys of birds were conducted at $1800-5400 \mathrm{~m}$ asl and could not be performed at lower or higher elevations because of geographic restrictions. We divided the study area into 12 elevational bands of $300 \mathrm{~m}$. Within each band, three transect lines that varied in length from 
170

171

172

173

174

175

176

177

2000-3000 m were distributed to cover all the habitat types (Fig. 1). Because biased samples can affect the observed species richness pattern (Rahbek, 1995; Rahbek, 2005), the total length of all transect lines in each band was restricted to $7.5 \mathrm{~km}$ to ensure that the sampling effort was equally distributed across the gradient.

We recorded the presence and abundance of bird species together with information regarding their position with a handheld GPS (Magellan eXplorist 310) using standard line transect methods (Bibby et al., 2000). To increase the probability of detecting elusive or rare species, for all transect lines, bird surveys were carried out four times throughout the entire wet season (from May to June in 2012, August in 2012, from September to October in 2012, and from July to August in 2013). The surveys were conducted between 30 min after dawn and 11 AM (local time) and between 3 PM and 30 min before sunset; the surveys were not conducted at mid-day or during inclement weather owing to low bird activity. The taxonomic system used in this study followed Zheng (2011).

\section{Species ranges}

We used breeding birds (breeding birds were defined as those birds that breed in the study area, i.e., resident birds and summer visitors) for subsequent analyses, owing to a potential bias in the elevational range size associated with seasonal, long-distance migrants (McCain, 2009; Wu et al., 2013b). Species were assumed to occur within a band if they were observed within higher and lower elevational bands (Colwell \& Hurtt, 1994; Colwell, Rahbek \& Gotelli, 2004). This interpolation method is commonly used and has been widely regarded as valid in previous studies (Rahbek, 1997; Brehm, Colwell \& Kluge, 2007; Wu et al., 2013b). In addition, it also avoids the underestimation of bird diversity owing to insufficient surveying of birds at both the temporal and spatial scale. The range size of each species was then transformed by " $n \times 300$ ” m (“ $n$ ” 
193 means the interpolated range of this species distributed over " $n$ " elevational bands) to conduct the 194 analyses described below.

195 Spatial factors

196 Area

197

We used GDEM 30-m digital elevation data from the International Scientific \& Technical

Data Mirror Site, Computer Network Information Center, Chinese Academy of Sciences (abbreviated as CNIC, CAS below; http://www.gscloud.cn/) to calculate the amount of threedimensional surface area for each 300-m elevational band in ArcGIS 10.2 (ESRI, Redlands, CA, USA).

\section{The mid-domain effect}

We used RangeModel 5 (Colwell, 2008; http://purl.oclc.org/range model) to randomize (without replacement) the empirical species ranges within the bounded domain to generate a predicted species richness pattern under geometric constraints (in the complete absence of any supposition of environmental gradients within the domain, see Colwell and Lees 2000 for details). Predicted values and their 95\% confidence intervals were computed for each 300-m band based on the mean of 5000 simulations of the geometrically constrained null model.

\section{Environmental factors}

\section{Mean annual temperature and mean annual precipitation}

Fine-scale climatic datasets covering the entire planet from the WorldClim database (http://www.worldclim.org) are based on information from many meteorological stations, augmented by statistical extrapolations to regions without meteorological stations by the use of digital elevation models (Hijmans et al., 2005). Thus, corresponding digital maps with a 
215 horizontal grid spacing of 30 arc-seconds and including information on elevation, mean annual 216 temperature, and mean annual precipitation were extracted from the WorldClim database (1950-

217 2000). We obtained the values of temperature and precipitation in each 300-m band by averaging

218 all grid cells within the band based on the elevational value of each grid cell in ArcGIS 10.2

219 (ESRI, Redlands, CA, USA).

220 Productivity

For the above-ground net primary productivity, we averaged the NDVI data for the Gyirong Valley from the Ministry of Environment Protection of the People’s Republic of China (http:// http://www.zhb.gov.cn) for each elevational band over four years (2011-2014) using ERDAS IMAGINE 9.2 (ERDAS, Norcross, GA, USA).

225

\section{Habitat heterogeneity}

$\mathrm{HH}$ was summarized using the Shannon diversity index (the abundance of one identified habitat type $=$ the area of that particular habitat type, richness $=$ the number of different habitat types), which is commonly applied at the landscape scale (Turner \& Gardner, 2015). We combined the GlobCover land cover data from CNIC, CAS (http://www.gscloud.cn/) and a 30-m digital elevation model (DEM) of the Gyirong Valley to calculate the area for each land-cover type in each 300-m elevational band using ArcGIS 10.2 (ESRI, Redlands, CA, USA). Twentytwo land-cover types are defined and primarily reflect the anthropogenic land use and the different types of forest, woodland, shrubland, and herbaceous communities.

\section{Data analyses}

To assess the effect of range size on the determinants of elevational patterns in species richness, we divided the overall species into two categories, the "large-ranged" category of 
237 species with ranges equal to or above the median size (elevational range size $1800 \mathrm{~m}$ ) and the "small-ranged” category of species with ranges below the median size (Wu et al., 2013a).

It is unlikely to detect all species in natural communities over limited time and space (Colwell \& Coddington, 1994; Chao et al., 2005; Walther \& Moore, 2005); thus, we used nonparametric estimators (Chao2 and Jackknife2) to compute the estimated species richness (Colwell \& Coddington, 1994) using the statistical software program EstimateS 9.0 (Colwell, 2013; http://purl.oclc.org/estimates). Regression of the observed species richness against the estimated species richness was then performed to assess whether species diversity was sampled adequately for the elevational gradient.

Polynomial regressions were performed to clarify the elevational distribution pattern of interpolated species richness as a function of elevation along the gradient. We used the corrected Akaike information criterion $\left(\mathrm{AIC}_{\mathrm{c}}\right)$ to compare the fits of first-order, second-order and thirdorder polynomial regressions, and smaller $\mathrm{AIC}_{\mathrm{c}}$ values indicated a better fit. Before relating species richness to candidate explanatory variables (Area, MDE, MAT, MAP, NDVI, and HH), we used Spearman's rank correlation to examine the relationships among the independent variables.

We performed simple ordinary least squares (OLS) regressions of the interpolated species richness for each species group (overall, large-ranged and small-ranged species) against each of the 6 candidate factors (Area, MDE, MAT, MAP, NDVI, and $\mathrm{HH}$ ) to explore the role of individual factors in shaping elevational species richness patterns. To correct for spatial autocorrelation in the regression residuals, we calculated the effective number of degrees of freedom for each regression and reported adjusted $P$-values based on the effective degrees of freedom (Dutilleul, 1993). 
patterns of bird species richness. For each species group (overall, large-ranged and small-ranged species), the best model was selected from the 63 models representing all possible combinations of 6 candidate explanatory variables (Area, MDE, MAT, MAP, NDVI, and HH), guided by the lowest AIC $_{c}$ (Anderson, Burnham \& White, 1998). However, there was sometimes nearly equivalent support for multiple models (i.e., nearly equal $\mathrm{AIC}_{\mathrm{c}}$ or $\Delta \mathrm{AIC}_{\mathrm{c}}$ values, i.e., $\Delta \mathrm{AIC}_{\mathrm{c}}<2$, see Table S5); thus, we used a model-averaging approach to compare the selected best models and assess the relative importance of different drivers by standardized beta coefficients (Anderson \& Burnham, 2002; Johnson \& Omland, 2004). variables could affect the credibility of the results and need to be taken into account (Diniz-Filho, Bini \& Hawkins, 2003; Graham, 2003). However, in the case of a limited sample size, it is not feasible to apply spatial autoregressive analyses with six explanatory variables. Thus, no $P$-values 273 were reported for the multiple regressions (Brehm, Colwell \& Kluge, 2007). To reduce the multicollinearity in the model, we conducted multiple OLS models without Area, AET, and AEP because they are highly correlated with NDVI (Table 1). Only MDE, NDVI and HH were tested in the multiple OLS regressions for all species groups (overall, large-ranged and small-ranged species). Because the collinearity among explanatory variables cannot be confidently resolved with such a small sample size (Graham, 2003), we furthermore performed partial regression for the different species groups (overall, large-ranged and small-ranged species) with three variables (MDE, NDVI, HH) partitioned into a spatial variable (MDE) and environmental variables variable and the environmental variables to the richness patterns. 
Table 1: Spearman correlation coefficients for the six selected factors.

\begin{tabular}{llllll}
\hline & Area & MAT & MAP & NDVI & HH \\
\hline Area & & & & & \\
MAT & $-0.993^{*}$ & & & & \\
MAP & $-0.993^{*}$ & $0.986^{*}$ & & & \\
NDVI & $-0.993^{*}$ & $0.986^{*}$ & $1^{*}$ & & \\
HH & 0.014 & -0.021 & 0 & 0 & $0.93^{*}$ \\
MDE & 0.126 & -0.14 & -0.112 & -0.112 & \\
\hline
\end{tabular}
ecoevol.ufg.br/sam).

\section{Elevational diversity patterns}



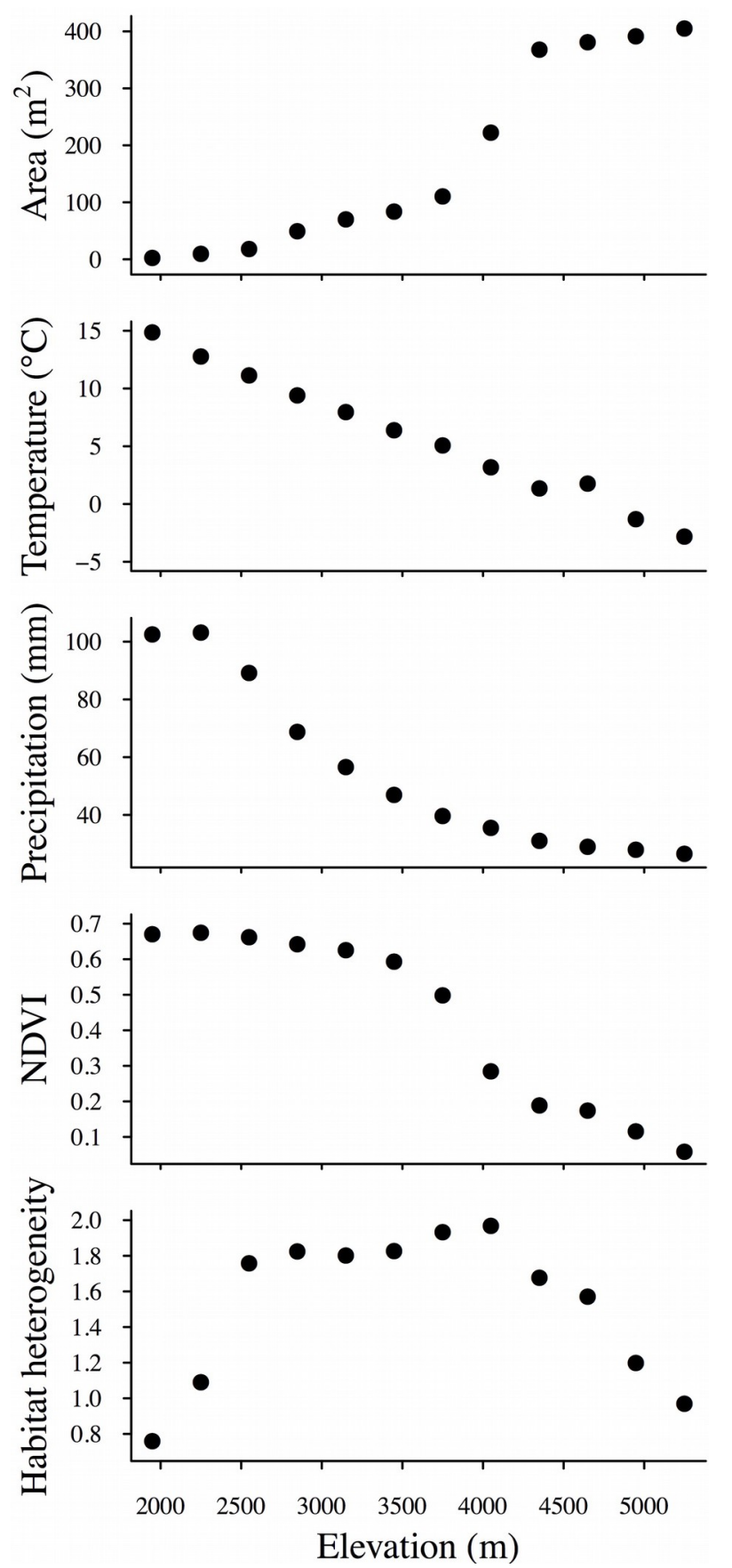

Figure 2: Elevational patterns of area, temperature, precipitation, NDVI (normalized difference vegetation index) and habitat heterogeneity. 
300 richness patterns along the elevational gradient.

301 The interpolated species richness showed hump-shaped patterns along the elevational

302 gradient (Fig. 3, Table S3). The species richness of overall birds peaked at 2700-3000 m asl. The 303 richness of large-ranged species peaked at 3300-3600 m asl, whereas that of small-ranged species 304 had two peaks, with the larger peak occurring at 2700-3000 $\mathrm{m}$ asl and the smaller peak occurring 305 at 3600-3900 $\mathrm{m}$ asl (Fig. 3).
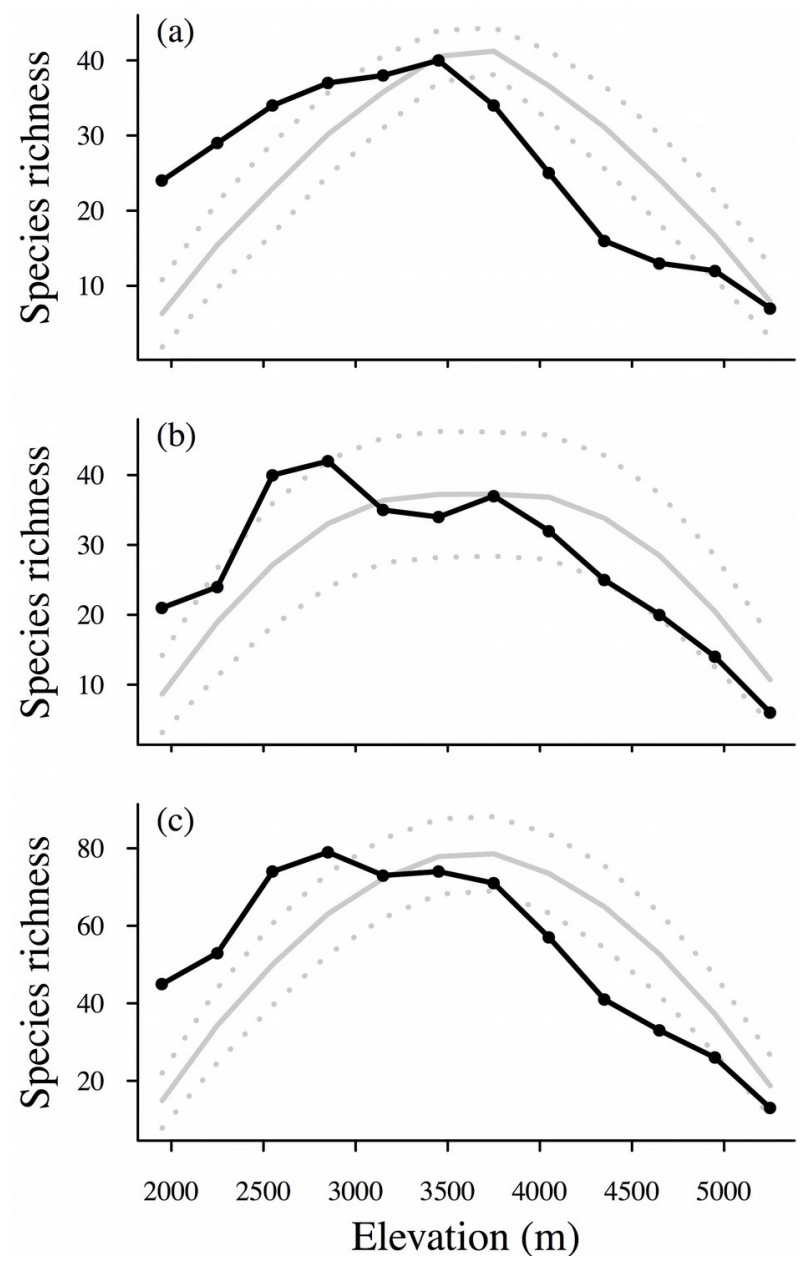

Figure 3: Elevational patterns of interpolated species richness. (a): large-ranged species; (b): small-ranged 
308 placement (MDE, the mid-domain effect) and the upper and lower 95\% confidence interval simulation limits 309 (gray dotted lines) are shown in the figure.

\section{Explanatory factors}

\section{Spatial factors}

312

Area was significantly correlated with the species richness of each species group in the simple OLS regressions (when spatial autocorrelation was not taken into account, Table 2). The beta coefficient for best-fit models (with the lowest $\mathrm{AIC}_{\mathrm{c}}$ values) showed that not all of the species groups were correlated with area (Table 3). According to the model-averaging analyses, area was negatively correlated with all bird groups (Table S4).

The MDE was significantly correlated with the species richness of all species groups in the simple OLS regressions (when spatial autocorrelation was not taken into account, Table 2). In the best-model-selection and the model-averaging analyses, MDE was only identified to be a weak predictor of the richness pattern of large-ranged species (Table 3, Table S4). The MDE played an important role in shaping the richness patterns of large-ranged species in the multiple OLS regressions with the three selected factors (to minimize multicollinearity, Table 4). In the partial regression analyses, the unique contribution of MDE to the richness patterns was weak for all the species groups (Table 5). 

six factors for different species groups.

\begin{tabular}{llllllll}
\hline & & \multicolumn{7}{c}{ Six factors } \\
\cline { 3 - 7 } Species groups & & Area & MAT & MAP & NDVI & HH & MDE \\
\hline Overall species & $\boldsymbol{r}^{2}$ & $0.632(-)$ & 0.386 & 0.169 & 0.654 & 0.684 & 0.446 \\
& $\boldsymbol{P}$ & $\mathbf{0 . 0 0 2}$ & $\mathbf{0 . 0 3 1}$ & 0.185 & $\mathbf{0 . 0 0 1}$ & $\mathbf{0 . 0 1 1}$ & $\mathbf{0 . 0 1 4}$ \\
& $\boldsymbol{P}_{\text {adj }}$ & 0.207 & 0.237 & 0.447 & 0.261 & 0.111 & 0.177 \\
Large-ranged & $\boldsymbol{r}^{2}$ & $0.741(-)$ & 0.46 & 0.234 & 0.763 & 0.307 & 0.344 \\
species & $\boldsymbol{P}$ & $<\mathbf{0 . 0 0 1}$ & $\mathbf{0 . 0 1 2}$ & 0.097 & $<\mathbf{0 . 0 0 1}$ & 0.052 & $\mathbf{0 . 0 3 7}$ \\
& $\boldsymbol{P}_{\text {adj }}$ & 0.452 & 0.308 & 0.397 & 0.498 & 0.243 & 0.292 \\
Small-ranged & $\boldsymbol{r}^{2}$ & $0.467(-)$ & 0.28 & 0.098 & 0.486 & 0.611 & 0.534 \\
species & $\boldsymbol{P}$ & $\mathbf{0 . 0 1 1}$ & 0.065 & 0.301 & $\mathbf{0 . 0 0 9}$ & $\mathbf{0 . 0 0 2}$ & $\mathbf{0 . 0 0 5}$ \\
& $\boldsymbol{P}_{\text {adj }}$ & 0.156 & 0.282 & 0.561 & 0.15 & $\mathbf{0 . 0 3 5}$ & 0.069 \\
\cline { 2 - 8 }
\end{tabular}

327 MAT, mean annual temperature; MAP, mean annual precipitation; NDVI, normalized difference vegetation 328 index; HH, habitat heterogeneity; MDE, the mid-domain effect. $P_{\text {adj }}$ is the adjusted $P$-value for $r^{2}$ based on the 329 adjustment of the degrees of freedom to account for spatial autocorrelation using Dutilleul's (1993) method. 330 Bold numbers indicate significant $r^{2}$ values $\left(P<0.05, P_{a d j}<0.05\right)$. Negative relationships are indicated by $(-)$.

\section{Environmental factors}

332 Most of the environmental factors, except for precipitation, were significantly correlated

333 with the species richness in each species group in the simple OLS regressions (when spatial

334 autocorrelation was not taken into account, Table 2).

335 The beta coefficient for best-fit models showed that temperature was only negatively ranged species (Table S4). 

small-ranged species in the model-averaging analyses (Table S4).

Table 3: Parameter estimates for the best-fit multiple regression models.

\begin{tabular}{|c|c|c|c|c|c|c|c|}
\hline \multirow[b]{2}{*}{ Species groups } & \multicolumn{7}{|c|}{ Standard coefficient of the best model } \\
\hline & Area & MAT & MAP & NDVI & HH & MDE & $r_{\text {adj }}^{2}$ \\
\hline Overall birds & & & & 0.728 & 0.584 & & 0.988 \\
\hline Large-ranged species & & -0.562 & & 1.352 & & 0.328 & 0.991 \\
\hline Small-ranged species & & & & 0.601 & 0.699 & & 0.962 \\
\hline
\end{tabular}

MAT, mean annual temperature; MAP, mean annual precipitation; NDVI, normalized difference vegetation

index; HH, habitat heterogeneity; MDE, the mid-domain effect. $r_{\text {adj }}^{2}$ is the adjusted $r^{2}$ value for multiple

regressions. For each species group (overall, large-ranged and small-ranged species), the best model was

NDVI, HH, MDE), guided by the lowest corrected Akaike information criterion value (AIC $\mathrm{A}_{\mathrm{c}}$ ). All 63 models

with their $\Delta \mathrm{AIC}_{\mathrm{c}}$ and $\mathrm{AIC}_{\mathrm{c}}$ weights for all species groups are reported in Supplemental Table S5. 
Table 4: Multiple ordinary least squares (OLS) regression of interpolated species richness against three

selected factors for different species groups.

\begin{tabular}{|c|c|c|c|c|c|}
\hline Species groups & NDVI & HH & MDE & $r^{2}$ & $\boldsymbol{P}$ \\
\hline Overall birds & 0.728 & 0.568 & 0.017 & 0.989 & $<0.001$ \\
\hline $\begin{array}{l}\text { Large-ranged } \\
\text { species }\end{array}$ & 0.804 & 0.06 & 0.408 & 0.974 & $<0.001$ \\
\hline $\begin{array}{l}\text { Small-ranged } \\
\text { species }\end{array}$ & 0.599 & 1.017 & -0.328 & 0.972 & $<0.001$ \\
\hline
\end{tabular}

357 MAT, mean annual temperature; MAP, mean annual precipitation; NDVI, normalized difference vegetation

358 index; HH, habitat heterogeneity; MDE, the mid-domain effect. Bold numbers indicate the parameters for each

359 multiple regression model that were significant at $P<0.05$.

360 In the partial regression analyses, the unique contributions of the environmental variables

361 (NDVI and $\mathrm{HH}$ ) to the richness patterns was stronger than that of MDE for all the species groups,

362 whereas the shared contribution varied among the species groups (32.4\%-52.8\%, Table 5).

Table 5: Partial regression for species richness of all bird groups with three selected factors partitioned

vegetation index; HH, habitat heterogeneity).

\begin{tabular}{|c|c|c|c|c|c|c|}
\hline $\begin{array}{l}\text { Species } \\
\text { groups }\end{array}$ & $\mathbf{a}$ & b & c & $\mathbf{a}+\mathbf{b}$ & $\mathbf{b}+\mathbf{c}$ & d \\
\hline Overall birds & $<0.001$ & 0.446 & 0.543 & 0.446 & 0.989 & 0.011 \\
\hline $\begin{array}{l}\text { Large-ranged } \\
\text { species }\end{array}$ & 0.02 & 0.324 & 0.631 & 0.344 & 0.955 & 0.026 \\
\hline $\begin{array}{l}\text { Small-ranged } \\
\text { species }\end{array}$ & 0.007 & 0.528 & 0.438 & 0.534 & 0.966 & 0.028 \\
\hline
\end{tabular}

366 ' $a$ ' and ' $c$ ' represent the unique contributions of spatial and environmental factors; ' $b$ ' is the shared contribution; ' $d$ '

367 is the unexplained variation; ' $a+b$ ' is the total contribution of the spatial factor to bird species richness; ' $b+c$ ' is the

368 total contribution of environmental factors to bird species richness. 


\section{Discussion}

\section{Elevational diversity patterns}

371 Our finding that the overall bird species richness peaked at intermediate elevations (2700-

3723000 m asl, Fig. 3) was consistent with most previous studies on mammals (Hu et al., 2014),

373 birds (Acharya et al., 2011; Joshi \& Bhatt, 2015), reptiles (Chettri, Bhupathy \& Acharya, 2010),

374 and plants (Grytnes \& Vetaas, 2002; Bhattarai, Vetaas \& Grytnes, 2004; Acharya, Vetaas \& Birks,

375 2011). The peak in richness is followed by a plateau at elevations of between $3000 \mathrm{~m}$ and $3900 \mathrm{~m}$

376 asl (Fig. 3). One possible explanation for this pattern is that the area between 3100 and $4000 \mathrm{~m}$

377 asl represents a transition zone between the Oriental and Palearctic regions (The Comprehensive

378 Scientific Expedition to Qinghai-Xizang Plateau, 1974; Li et al., 2013), and such a pattern might

379 provide new evidence for the hypothesis that ecotones between different faunas harbor more

380 species (Brown, 1995).

$381 \quad$ Fu et al. (2006) and Brehm, Colwell RK \& Kluge (2007) found that large-ranged species 382 contribute more to overall richness patterns than small-ranged species, but our results were not 383 consistent with this observation because the correlation coefficient between large-ranged and 384 overall species was equal to that between small-ranged and overall species (both $r^{2}=0.942, P<$ 385 0.01). The equal contributions of groups with different range sizes to the overall richness pattern 386 was perhaps due to the larger number of small-ranged species relative to that of large-ranged 387 species (125 versus 44).

388 Spatial factors

The most recent synthetic analysis at a global scale found no consistent support for the influence of area on bird species richness along elevational gradients (McCain, 2009). The 
variability in area effects was largely attributed to the shape of the richness-elevation relationship and the area-elevation relationship (McCain, 2007a). A strong richness-area relationship was expected when both variables show concordant patterns along the elevational gradient. In this study, area increased monotonically with elevation (which was different from the patterns commonly observed for mountains), making Gyirong Valley an exceptional test system for evaluating the importance of area on species richness patterns. A negative relationship between species richness and area was demonstrated for all the groups in both individual regression analyses (Table 2) and multi-model analyses (Table S4), and not all the species groups were correlated with area in the best models (Table 3), indicating that area was not a crucial factor in determining species richness in the present study. Furthermore, Rahbek (1997) argued that it is not ground area per se that determines species richness but rather the volume of available habitat. In the Gyirong Valley, although the highest elevational bands harbored a larger area, the climate was cold and arid, resulting in unsuitable habitat for most bird species.

The MDE was an important variable in explaining species richness patterns along the elevational gradient based on the individual regression analyses (Table 2), but when considered in combination with other candidate factors using multi-model inference, the MDE appeared to be a weak predictor for all the species groups except for large-ranged species (Table 3, Table 4, Table S4). The MDE should be more pronounced when larger ranges are considered (Colwell \& Lees, 2000; Colwell, Rahbek \& Gotelli, 2004). In our study, the explanatory power of the MDE was also found to be stronger for large-ranged species than for small-ranged species in the multiple regressions (Table 3, Table 4, Table S4). The weaker explanatory power of the MDE in the species richness of the other bird groups was in some ways due to collinearity among explanatory variables because the variation shared with the MDE was “captured” by environmental factors 
414 (Table 4, Table 5). Our results highlight that both individual and multiple regression are important 415 to develop a deeper understanding of the mechanisms underlying diversity patterns. In the present 416 case, the species richness of all the bird groups peaked at lower elevations than predicted by the 417 MDE null model, suggesting that other factors had modified the influence of the MDE.

\section{Environmental factors}

in the eastern Himalayas. In our study, the climate-richness relationship was supported, whereas

the explanatory power of temperature and precipitation varied across the different species groups climates would harbor the most species on mountains (Wiens \& Donoghue, 2004; Wiens \& Graham, 2005); our results did not coincide with this prediction because the species richness did not decrease with decreasing temperature and precipitation along the elevational gradient. However, the climate data were not generated locally in this study because there were no meteorological stations in the Gyirong Valley. Considering the complex topography and various microhabitats on mountains, more high-quality, small-scaled and long-term data on climate factors such as rainfall, humidity, and cloud cover need to be collected along elevational gradients to more accurately generate climatic models.

Productivity was strongly correlated with the species richness of all bird groups (Table 3, Table S4). In the multiple OLS regression excluding Area, AET, and AEP to reduce multicollinearity, productivity played a statistically more explanatory role in shaping the richness patterns of all bird groups (Table 4). Our results added support for the utility of satellite-derived vegetation indices as proxies of productivity and revealed new evidence for the energy-diversity hypothesis. 
$\mathrm{HH}$ was identified as an important predictor of the species-elevation relationship for all the bird groups except for large-ranged birds in the present study. The weak explanatory power of

$\mathrm{HH}$ in explaining the richness patterns of large-ranged birds might be attributed to two issues: 1 ) the "large-ranged" birds were distributed more widely across the elevational gradient; thus, they were more adaptable and could adapt to more habitat types (White \& Bennett, 2015) and tended to be habitat generalists in this area (relative to the "small-ranged” birds). The large number of habitat generalists might result in incongruence between habitat heterogeneity and species richness (Rowe, Heaney \& Rickart, 2015); 2) the measures of habitat diversity used so far failed to capture critical microhabitat differences in composition or structural complexity that may influence the diversity of large-ranged birds. Our results call for caution when assessing the role of $\mathrm{HH}$ in shaping species richness patterns, especially for those groups of taxa that contain a large number of species, and the measure used should adequately reflect habitat use by the species groups studied.

\section{Biodiversity conservation}

The Gyirong Valley harbors 47\% of the bird species recorded in the Mount Qomolangma

National Nature Reserve, based on our field survey and the research of Li et al. (2013). Most of the breeding birds (74\%) in the Gyirong Valley are small-ranged (i.e., elevational range size of below $1800 \mathrm{~m}$ ). Species with smaller elevational ranges are at a greater risk of extinction than species with larger elevational ranges (White \& Bennett, 2015), and small-ranged species on mountains would be more threatened under global warming (Colwell et al., 2008), highlighting the need for increased conservation efforts in this area. The species richness of overall birds

458 peaked at mid-elevations; however, the mid-elevational area is influenced by strong 
460 461 462

our observations during the field survey). Anthropogenic habitat alterations and shifts in land use patterns could exacerbate the challenges of global warming faced by montane birds (Colwell et al., 2008; McCain \& Colwell, 2011). In our study, the species richness of overall birds was positively correlated with productivity and habitat heterogeneity, indicating that the existing primary forest in this valley is important for biodiversity conservation and that changes in land use should avoid reducing the availability and connectivity of suitable habitats along the gradient. In the present case, our knowledge of anthropogenic threats is still limited; thus, long-term monitoring and applied research are needed in this montane biodiversity hotspot to provide more valuable insights for biodiversity conservation.

\section{Conclusions}

The species richness of all the bird groups in the Gyirong Valley of the central Himalayas peaked at mid-elevations, and the different species groups showed different richness patterns along the elevational gradient. No single factor or suite of factors could explain the species richness patterns across all the bird groups. The important roles of productivity and $\mathrm{HH}$ in shaping the elevational richness patterns of most bird species groups highlights the need to conserve intact habitat in this montane biodiversity hotspot.

\section{Acknowledgements}

We thank numerous graduates in our group for the bird surveys in the field. We also thank

Dr. Zhixin Zhou and Dr. Daoying Lan for providing extensive comments on the draft manuscript. References 
Acharya BK, Sanders NJ, Vijayan L, Chettri B. 2011. Elevational gradients in bird diversity in the eastern Himalaya: an evaluation of distribution patterns and their underlying mechanisms. PloS ONE 6: 4932-4937.

Acharya KP, Vetaas OR, Birks HJB. 2011. Orchid species richness along Himalayan elevational gradients. Journal of Biogeography 38: 1821-1833.

Anderson DR, Burnham KP, White GC. 1998. Comparison of Akaike information criterion and consistent Akaike information criterion for model selection and statistical inference from capture-recapture studies. Journal of Applied Statistics 25: 263-282.

Anderson DR, Burnham KP. 2002. Avoiding pitfalls when using information-theoretic methods. Journal of Wildlife Management 66: 912-918.

Bhattarai KR, Vetaas OR. 2003. Variation in plant species richness of different lifeforms along a subtropical elevation gradient in the Himalayas, east Nepal. Global Ecology and Biogeography 12: 327-340.

Bhattarai KR, Vetaas OR, Grytnes JA. 2004. Fern species richness along a central Himalayan elevation gradient, Nepal. Journal of Biogeography 31: 398-400.

Bhattarai KR, Vetaas OR. 2006. Can Rapoport's rule explain tree species richness along the Himalayan elevation gradient, Nepal? Diversity and Distributions 12: 373-378.

Bibby CJ, Burgess ND, Hill DA, Mustoe S. 2000. Bird Census Techniques. 2nd edn. London: Academic Press.

Brehm G, Colwell RK, Kluge J. 2007. The role of environment and mid-domain effect on moth species richness along a tropical elevational gradient. Global Ecology and Biogeography 16: 205-219.

Brown JH. 1995. Macroecology. Chicago: University of Chicago Press. 
503 Cardelús CL, Colwell RK, Watkins JEJR. 2006. Vascular epiphyte distribution patterns:

504 explaining the mid-elevation richness peak. Journal of Ecology 94: 144-156.

505 Chao A, Chazdon RL, Colwell RK, Shen TJ. 2005. A new statistical approach for assessing

506 similarity of species composition with incidence and abundance data. Ecology Letters 8:

$507 \quad 148-159$

508 Chettri B, Bhupathy S, Acharya BK. 2010. Distribution pattern of reptiles along an eastern

$509 \quad$ Himalayan elevation gradient, India. Acta Oecologica 36: 16-22.

510 Colwell RK, Coddington JA. 1994. Estimating terrestrial biodiversity through extrapolation.

$511 \quad$ Philosophical Transactions of the Royal Society (Series B) 345: 101-118.

512 Colwell RK, Hurtt GC. 1994. Nonbiological gradients in species richness and a spurious

$513 \quad$ Rapoport effect. The American Naturalist 144: 570-595.

514 Colwell RK, Lees DC. 2000. The mid-domain effect: geometric constraints on the geography of $515 \quad$ species richness. Trends in Ecology and Evolution 15: 70-76.

516 Colwell RK, Rahbek C, Gotelli NJ. 2004. The mid-domain effect and species richness patterns:

$517 \quad$ what have we learned so far? The American Naturalist 163: E1-E23.

518 Colwell RK. 2008. RangeModel: Tools for exploring and assessing geometric constraints on $519 \quad$ species richness (The mid-domain effect) along transects. Ecography 31: 4-7.

520 Colwell RK, Brehm G, Cardelús CL, Gilman AC, Longino JT. 2008. Global warming, elevational 521 range shifts, and lowland biotic attrition in the wet tropics. Science 322:, 258-261.

522 Colwell RK. 2013. EstimateS (data analysis software system and user’s guide), version 9.0.

$523 \quad$ Available at: http://viceroy.eeb.uconn.edu/estimates/. 
524 Currie DJ, Mittelbach GG, Cornell HV, Field R, Guégan JF, Hawkins BA, Kaufman DM, Kerr

525 JT, Oberdorff T, O’Brien E, Turner JRG. 2004. Predictions and tests of climate-based

526 hypotheses of broad-scale variation in taxonomic richness. Ecology Letters 7: 1121-1134.

527 Diniz-Filho JAF, Bini LM, Hawkins BA. 2003. Spatial autocorrelation and red herrings in 528 geographical ecology. Global Ecology and Biogeography 12: 53-64.

Dirzo R, Raven PH. 2003. Global state of biodiversity and loss. Annual Review of Environmental Resources 28: 137-167.

Dobremez JF. 1976. Le Népal, Écologie et Biogéographie. Paris: Centre National de la Pecherche Scientifique.

Dutilleul P. 1993. Modifying the T-test for assessing the correlation between two spatial processes. Biometrics 49: 305-314.

Feng ZJ, Cai GQ, Zheng CL. 1986. The mammals of Xizang. Beijing: Science Press.

Fu CZ, Wu JH, Wang XY, Lei GC, Chen JK. 2004. Patterns of diversity, altitudinal range and body size among freshwater fishes in the Yangtze River basin, China. Global Ecology and Biogeography 13: 543-552.

Fu CZ, Hua X, Li J, Chang Z, Pu ZC, Chen JK. 2006. Elevational patterns of frog species richness and endemic richness in the Hengduan Mountains, China: geometric constraints, area and climate effects. Ecography 29: 919-927.

Graham MH. 2003. Confronting multicollinearity in ecological multiple regression. Ecology 84: 2809-2815.

Grytnes JA, Vetaas OR. 2002. Species richness and altitude: a comparison between null models and interpolated plant species richness along the Himalayan altitudinal gradient, Nepal. The American Naturalist 159: 294-304. 
547

Grytnes JA, McCain CM. 2007. Elevational trends in biodiversity. In: Levin SA, ed. Encyclopedia of Biodiversity. Oxford: Elsevier, 1-8.

Hammer Ø, Harper DAT, Ryan PD. 2001. PAST: paleontological statistics software package for education and data analysis. Palaeontologia Electronica 4: 1-9.

Hawkins BA, Diniz-Filho JAF, Soeller SA. 2005. Water links the historical and contemporary components of the Australian bird diversity gradient. Journal of Biogeography 32: 10351042.

Hawkins BA, Diniz-Filho JAF, Jaramillo CA, Soeller SA. 2007. Climate, niche conservatism, and the global bird diversity gradient. The American Naturalist 170: S16-S27.

Heaney LR. 2001. Small mammal diversity along elevational gradients in the Philippines: an assessment of patterns and hypotheses. Global Ecology and Biogeography 10: 15-39.

Hijmans RJ, Cameron SE, Parra JL, Jones PG, Jarvis A. 2005. Very high resolution interpolated climate surfaces for global land areas. International Journal of Climatology 25: 1965-1978.

Hu H, Jin K, Tian Y. 2016. Wild vetebrates in Qomolangma National Natural Reserve, China. Guangzhou: Guangdong Sci \& Tech. Press.

Hu YM, Yao ZJ, Huang ZW, Tian Y, Li HB, Pu Q, Yang DD, Hu HJ. 2014. Mammalian fauna and its vertical changes in Mt. Qomolangma National Nature Reserve, Tibet, China. Acta Theriologica Sinica 34: 28-37.

Hunter ML, Yonzon P. 1993. Altitudinal distributions of birds, mammals, people, forests, and parks in Nepal. Conservation Biology 7: 420-423.

Hurlbert AH, Haskell JP. 2003. The effect of energy and seasonality on avian species richness and community composition. The American Naturalist 16: 83-97. 
569 570

571

Hurlbert AH. 2004. Species-energy relationship and habitat complexity in bird communities. Ecology Letters 7: 714-720.

Hutchinson GE. 1959. Homage to Santa Rosalia, or "why are there so many kinds of animals". The American Naturalist 93: 145-159.

Johnson JB, Omland KS. 2004. Model selection in ecology and evolution. Trends in Ecology and Evolution 19: 101-108.

Joshi K, Bhatt D. 2015. Avian species distribution along elevation at doon valley (foot hills of western Himalayas), Uttarakhand, and its association with vegetation structure. Journal of Asia-Pacific Biodiversity 26: 158-167.

Kattan GH, Franco P. 2004. Bird diversity along elevational gradients in the Andes of Colombia: area and mass effects. Global Ecology and Biogeography 13: 451-458.

Kluge J, Kessler M, Dunn RR. 2006. What drives elevational patterns of diversity? A test of geometric constraints, climate and species pool effects for pteridophytes on an elevational gradient in Costa Rica. Global Ecology and Biogeography 15: 358-371.

Koh CN, Lee PF, Lin RS. 2006. Bird species richness patterns of northern Taiwan: primary productivity, human population density, and habitat heterogeneity. Diversity and Distributions 12: 546-554.

Lee PF, Ding TS, Hsu FH, Geng S. 2004. Breeding bird species richness in Taiwan: distribution on gradients of elevation, primary productivity and urbanization. Journal of Biogeography 31: 307-314.

Li JJ, Han LX, Cao HF, Tian Y, Peng BY, Wang B, Hu HJ. 2013. The fauna and vertical distribution of birds in Mount Qomolangma National Nature Reserve. Zoological Research 34: $531-548$ 
592 Lomolino MV. 2001. Elevation gradients of species-density: historical and prospective views. $593 \quad$ Global Ecology and Biogeography 10: 3-13.

594 MacArthur RH, MacArthur JW. 1961. On bird species diversity. Ecology 42: 594-598.

595 MacArthur RH. 1972. Geographical ecology. New York: Harper and Rowe Publishers.

596 McCain CM. 2004. The mid-domain effect applied to elevational gradients: species richness of 597 small mammals in Costa Rica. Journal of Biogeography 31: 19-31.

598 McCain CM. 2005. Elevational gradients in diversity of small mammals. Ecology 86: 366-372.

599 McCain CM. 2007a. Area and mammalian elevational diversity. Ecology 88: 76-86.

600 McCain CM. 2007b. Could temperature and water availability drive elevational species richness 601 patterns? A global case study for bats. Global Ecology and Biogeography 16: 1-13.

602 McCain CM. 2009. Global analysis of bird elevational diversity. Global Ecology and

603 Biogeography 18: 346-360.

604 Myers N, Mittermeier RA, Mittermeier CG, da Fonseca GAB, Kent J. 2000. Biodiversity

605 hotspots for conservation priorities. Nature 403: 853-858.

606 Nogués-Bravo D, Araújo MB, Romdal T, Rahbek C. 2008. Scale effects and human impact on the 607 elevational species richness gradients. Nature 453: 216-219.

608 Oommen MA, Shanker K. 2005. Elevational species richness patterns emerge from multiple local 609 mechanisms in Himalayan woody plants. Ecology 86: 3039-3047.

610 Price TD, Hooper DM, Buchanan CD, Johansson US, Tietze DT, Alström P, Olsson U, Ghosh611 Harihar M, Ishtiaq F, Gupta SK, Martens J, Harr B, Singh P, Mohan D. 2014. Niche filling 612 slows the diversification of Himalayan songbirds. Nature 509: 222-225.

613 Rahbek C. 1995. The elevational gradient of species richness: a uniform pattern? Ecography 18: $614 \quad 200-205$ 
615 Rahbek C. 1997. The relationship among area, elevation, and regional species richness in $616 \quad$ Neotropical birds. The American Naturalist 149: 875-902.

617 Rahbek C. 2005. The role of spatial scale and the perception of large-scale species-richness $618 \quad$ patterns. Ecology Letters 8: 224-239.

619 Rangel TF, Diniz-Filho JAF, Bini LM. 2010. SAM: a comprehensive application for Spatial 620 Analysis in Macroecology. Ecography 33: 46-50.

621 Rohde K. 1992. Latitudinal gradients in species diversity: the search for the primary cause. Oikos $622 \quad 65: 514-527$.

623 Rowe RJ. 2009. Environmental and geometric drivers of small mammal diversity along 624 elevational gradients in Utah. Ecography 32: 411-422.

625 Rowe RJ, Heaney LR, Rickart EA. 2015. Scale effects on the pattern and predictors of small mammal diversity along a local elevational gradient in the great basin. Journal of Biogeography 42: 1964-1974.

628 Sánchez-Cordero V. 2001. Elevation gradients of diversity for rodents and bats in Oaxaca, 629 Mexico. Global Ecology and Biogeography 10: 63-76.

630 Sanders NJ, Rahbek C. 2012. The patterns and causes of elevational diversity gradients. $631 \quad$ Ecography 35: 1-3.

632 Stevens GC. 1992. The elevational gradient in altitudinal range: an extension of Rapoport's 633 latitudinal rule to altitude. The American Naturalist 140: 893-911. 634 The Comprehensive Scientific Expedition to Qinghai-Xizang Plateau, Chinese Academy of 635 Sciences. 1988. Vegetation of Xizang. Beijing: Science Press. 
636 Tibetan scientific expedition of Chinese Academy of Sciences. 1974. The report of the scientific 637 investigation to Mt. Qomolangma region-Biology and alpine physiology. Beijing: Science $638 \quad$ Press.

639 Turner MG, Gardner RH. 2015. Landscape ecology in theory and practice: pattern and process. $640 \quad$ 2nd edn. New York: Springer.

641 Walther BA, Moore JL. 2005. The concepts of bias, precision and accuracy, and their use in 642 testing the performance of species richness estimators, with a literature review of estimator 643 performance. Ecography 28: 815-829.

644 White RL, Bennett PM. 2015. Elevational distribution and extinction risk in birds. PloS ONE 10: $645 \quad$ e0121849.

646 Wiens JJ, Donoghue MJ. 2004. Historical biogeography, ecology and species richness. Trends in $647 \quad$ Ecology \& Evolution 19: 639-644.

648 Wiens JJ, Graham CH. 2005. Niche conservatism: integrating evolution, ecology, and 649 conservation biology. Annual Review of Ecology, Evolution, and Systematics 36: 519-539.

650 Wiens JJ. 2011. The causes of species richness patterns across space, time, and clades and the 651 role of "ecological limits". Quarterly Review of Biology 86: 75-96.

652 Williams SE, Shoo LP, Henriod R, Pearson RG. 2010. Elevational gradients in species 653 abundance, assemblage structure and energy use of rainforest birds in the Australian wet $654 \quad$ tropics bioregion. Austral Ecology 35: 650-664.

655 Wright DH. 1983. Species-energy theory: an extension of species-area theory. Oikos 41: 496-506. 656 Wu YJ, Yang QS, Wen ZX, Xia L, Zhang Q, Zhou HM. 2013a. What drives the species richness 657 patterns of non-volant small mammals along a subtropical elevational gradient? Ecography $658 \quad 36: 185-196$. 
659 Wu YJ, Colwell RK, Rahbek C, Zhang CL, Quan Q, Wang CK, Lei FM. 2013b. Explaining the 660 species richness of birds along an elevational gradient in the subtropical Hengduan 661 Mountains. Journal of Biogeography 40: 2310-2323.

662 Zheng GM. 2011. A checklist on the classification and distribution of the birds of China. 2nd edn. 663 Beijing: Science Press. 